\title{
O USUÁRIO NO PROCESSO DE PROJETO DE DESIGN DE INTERIORES
}

\author{
FLORES, Laura Zimmermann \\ UFSC, e-mail: pro.lauraflores@gmail.com \\ MERINO, Giselle Schmidt Alves Díaz \\ UFSC, e-mail: gisellemerino@gmail.com
}

\begin{abstract}
RESUMO
Este artigo apresenta um olhar para metodologias utilizadas no processo de projeto de espaços interiores no meio acadêmico, com uma abordagem voltada ao usuário e às relações que estabelece com o ambiente construído. Tendo em vista a importância da consideração do usuário no contexto ambiental, o presente artigo tem como objetivo identificar como o usuário é considerado no processo de projeto de espaços interiores. A base da metodologia para projetos interiores costuma advir do projeto arquitetônico, enquanto algumas instituições optam por consultar as metodologias voltadas ao desenvolvimento de produto. Por meio de uma pesquisa nas bases do sistema e-mec identificou-se as instituições públicas que oferecem este curso no país, em seguida as bibliografias específicas de design de interiores utilizadas por elas em disciplinas de metodologia de projeto. Apresenta-se como os autores sugerem que 0 projetista contacte ou considere os usuários e de que maneira devem ser abordados durantes as etapas do projeto. Verificou-se que as etapas metodológicas apresentadas, de forma geral, não prevêem a consideração do usuário no processo de projeto, apenas em algumas situações, apontam os momentos de interação entre projetista e cliente visando possíveis ajustes projetuais.
\end{abstract}

Palavras-chave: design de interiores; metodologia de projeto; usuário; ambiente construído.

\begin{abstract}
This article presents a look at methodologies used in the design process of interior spaces in the academic environment, with a user - oriented approach and the relationships established with the built environment. Considering the importance of user consideration in the environmental context, this article aims to identify how the user is considered in the process of designing interior spaces. The basis of the methodology for interior projects usually comes from the architectural design, while some institutions choose to consult the methodologies focused on product development. Through a search in the bases of the e-mec system, the public institutions that offered this course in the country were identified, followed by the specific bibliographies of interior design used by them in disciplines of design methodology. It is presented as the authors suggest that the designer contact or consider the users and how they should be approached during the project steps. It was verified that the methodological steps presented, in general, do not foresee the consideration of the user in the design process, only in some situations, point the moments of interaction between designer and client aiming at possible design adjustments.
\end{abstract}

Keywords: interior design; project metodology; user; environmental construct.

\section{INTRODUÇÃO}

Diversos são os profissionais que atuam com projetos de design de ambientes, sejam eles de grande ou de pequena escala. Pode-se citar, por exemplo, arquitetos, designers, designers de interiores. Cada qual com seu ponto de

FLORES, L. Z.; MERINO, G. S. A. D. O usuário no processo de projeto de design de interiores. In: SIMPÓSIO BRASILEIRO DE QUALIDADE DO PROJETO NO AMBIENTE CONSTRUÍDO, 6., 2019, Uberlândia. Anais... Uberlândia: PPGAU/FAUeD/UFU, 2019. p. 1578-1587. DOI https://doi.org/10.14393/sbqp19142. 
vista, observa o processo de projeto e as necessidades requeridas pelo usuário de diferentes maneiras. A literatura orienta estudantes dessas áreas com métodos de projeto a serem seguidos. Em algumas, encontra-se os termos "usuário", mas o termo "cliente" - mesmo quando este usará o espaço - é mais comum de se encontrar. Segundo Oliveira (2016) o ato de projetar requer criatividade, repertório de informação, conhecimento e experiência, além do desafio de definir os problemas do usuário com exatidão e conseguir propor soluções considerando todos os níveis de necessidades a serem atendidos. Segundo o autor

Naturalmente, por ser uma atividade praticada por três formações diferentes, não é exatamente um fator surpresa que cada profissional, à sua maneira, desenvolva suas atividades baseados em métodos de projeto aos quais tiveram acesso na academia e/ou seu modus faciendi. Ou seja, os profissionais, de posse do conhecimento que adquirem durante sua formação acadêmica, aplicam (ou tentam aplicar) os processos de projeto (métodos) conforme seu entendimento na busca da solução projetual pretendida. (p.17)

Moser (2005) traz que as intervenções que se referem principalmente ao habitat e design de espaços coletivos estão baseadas em colaborações multidisciplinares entre arquitetos, designers e cientistas humanos. Independente da formação do profissional projetista, levar em consideração questões como psicologia ambiental e ergonomia são fundamentais para que, ao seguir a metodologia proposta, necessidades e questões do usuário não sejam perdidas ao longo do processo.

Tendo em vista tais questões, e visando contribuir para a ampliação da qualidade de projetos de ambientes interiores sob a perspectiva do usuário, o presente artigo tem como objetivo identificar como este usuário é considerado no processo de projeto apontado por literatura em design de interiores, e quais são as etapas chave onde o mesmo é abordado. A literatura apresenta bases metodológicas que costumam ser referência para o desenvolvimento de projeto no meio acadêmico, aprendizado que é levado para a prática projetual pós formação.

Assim, analisa-se algumas metodologias de projetos de design de interiores presentes nas bibliografias de alguns cursos de graduação em design de interiores, e a partir de alguns diagramas que as representam, identifica-se as etapas nas quais os autores explicitam algo a respeito das relações usuárioambiente, ou na sua ausência, os momentos a que se deve recorrer ao cliente para possíveis ajustes ou feedback.

\section{REVISÃO BIBLIOGRÁFICA}

\subsection{O usuário e as metodologias}

Munari (1998), em sua obra "Das coisas nascem coisas" aborda a importância de não se confundir um projeto criativo com um projeto sem método. Para Oliveira (2016), o método de projeto em design de interiores exige certa complexidade, e pode ser derivado de conhecimentos acadêmicos, técnicos ou ainda associados à prática e ao repertório do profissional. Em projetos de design de interiores, em geral, as metodologias diferem em suas técnicas se comparadas às propostas ao projeto de design de produto. Isso por que, no caso de projeto de ambientes costuma-se ter contato direto com o usuário 
e/ou cliente, além disso, cada projeto será único, diferentemente do desenho industrial, que por vezes é replicado em maior escala, e portanto não se garante o contato com o usuário final.

Para Iwata, Rocha e Saleiro Filho (2003) o processo de projeto de interiores se assemelha, em partes ao projeto arquitetônico, diferenciando-se em sua escala. Para Kowaltowski et al (2006) o processo de projeto é como um conjunto de atividades intelectuais que são organizadas em fases, cada qual com sua característica e/ou resultado específico. Oliveira (2016) afirma que o termo "necessidade do usuário" tornou-se uma expressão chave em projetos dessa natureza, que atender a elas é o objetivo central de projeto, seja qual for o campo. Para Moreira e Kowaltowski (2009) o usuário é o elemento ativo do contexto, e o programa de necessidades - primeiro passo do processo de projeto - deve ser desenvolvido com foco no mesmo.

Para Oliveira (2016) a ampliação da qualidade projetual pode ser adquirida pela contribuição dos ensinamentos da ergonomia. Costa e Villarouco (2016) afirmam que a ergonomia do ambiente construído, quando inserida já na fase projetual, atua como prevenção a possíveis problemas. Atualmente, métodos que propõem a avaliação ergonômica e o estudo do ambiente - neste caso na pós concepção, como Avaliação Pós Ocupação (APO) ou Metodologia Ergonômica do Ambiente Construído (MEAC) auxiliam na minimização de erros em novos projetos. No entanto, as autoras afirmam que o fluxo do processo de projeto arquitetônico não costuma prever a ergonomia durante o processo de projeto, e portanto representaria romper com sua prática comum. Elali (1997), em seus estudos acerca da psicologia ambiental, afirma a importância dos trabalhos avaliativos como subsídios a novos projetos ou ainda na manutenção de espaços construídos. A autora ainda afirma que as preocupações com as questões físicas, estéticas e construtivas, no que tange - projeto por parte de arquitetos, têm perdido sua ênfase para a preocupação com as questões de percepção e satisfação, dando espaço para propostas projetuais mais centradas no indivíduo. Para isso, Elali reforça a importância para a "análise do uso" visando transformar espaços em lugares, valorizando o ponto de vista do usuário.

Certamente as pessoas comuns pouco conhecem sobre a fabricação de
brinquedos, por exemplo. No entanto, após algum uso as crianças são capazes
de dizer/demonstrar se um determinado produto é adequado ou não às suas
brincadeiras; os pais compreendem seu potencial de uso ou sua periculosidade;
os professores julgam aspectos pedagógicos de sua adoção em sala de aula;
os psicólogos os consideram eficazes ou não no processo terapêutico com
pacientes de determinada faixa etária etc. Assim, embora nenhum desses
usuários possa ser considerado "especialista" na fabricação de brinquedos, a
função uso os habilita a realizar tal análise, sendo suas percepções individuais
elementos determinantes na avaliação do objeto, o que define cada um
desses extratos da população como uma fonte potencial de críticas ao
produto, propiciando sua alteração para melhor adequação ao público-alvo
(os próprios usuários). Apesar desta prática ser comum ao setor industrial, ainda
é (desconcertantemente) embrionária no âmbito da construção dos edifícios
que nos abrigam durante toda a vida. (p. 354)

Segundo Merino (2018) o Design Centrado no Usuário é uma estrutura de processos em que objetivos, usabilidade, características do usuário, ambiente, tarefas e fluxo de trabalho de um produto, serviço ou processo recebem ampla atenção em cada estágio do processo de design. A autora afirma que o usuário deve participar do processo como alguém que tem preferências 
(pesquisa de contexto), como provedor de informações específicas (cocriação) e como utilizador do produto (testes de usabilidade e prototipagem). Segundo Merino, quando nos referimos a projetos centrados no ser humano devemos tratar das capacidades humanas - sensorial, cognitiva e motora - e das dimensões - temporal (nascer, crescer e envelhecer) e social (aspectos culturais e de contexto).

\section{METODOLOGIA}

Este artigo se caracteriza como uma pesquisa qualitativa, e quanto à natureza do seu objetivo é uma pesquisa exploratória. Com base em uma breve pesquisa, realizada junto ao sistema e-mec, por IES que oferecem cursos de Design de Interiores, foram encontrados 284 resultados. Os mesmos foram filtrados em busca das instituições federais, tendo em vista que estas disponibilizam ao público seu Projeto Pedagógico de maneira online. Foram identificadas, portanto, cinco instituições federais: UFU- Universidade Federal de Uberlândia, que tem como denominação do curso apenas "Design", mas, segundo o E-mec, no passado o curso era denominado Design de Interiores, e está atualmente unido ao departamento do curso de Arquitetura e Urbanismo; o IFAL - Instituto Federal de Alagoas; IFPB - Instituto Federal da Paraíba; IFSP Instituto Federal de São Paulo e IFMG - Instituto Federal de Minas Gerais.

Após este levantamento, uma segunda pesquisa em busca dos projetos pedagógicos dos cursos (PPC'S) foi realizada online. Em cada um dos PPC's buscou-se o ementário das disciplinas de Metodologia de Projeto e as bibliografias básicas das mesmas. Algumas instituições não possuem em sua matriz curricular esta disciplina, como é o caso da UFU, que tem no ementário da disciplina de Ateliê de Design de Interiores - Introdução ao Design, o objetivo de introduzir ao aluno as metodologias de projeto. Portanto, na ausência da disciplina de Metodologia, buscou-se a bibliografia básica da primeira disciplina de Projeto da Matriz Curricular.

Após o levantamento das bibliografias, buscou-se identificar àquelas que tivessem maior afinidade com a área de Design de Interiores, excluindo-se as voltadas a assuntos mais genéricos, os voltados ao projeto arquitetônico ou projeto de produtos. Chegou-se então a quatro autores cujas bibliografias foram observadas brevemente, identificando suas etapas específicas e os momentos nos quais o usuário está em foco. Abaixo uma figura elaborada para expor as bibliografias levantadas por instituição, identificando em vermelho os autores abordados no próximo item deste artigo. 


\begin{tabular}{|c|c|}
\hline INSTITUIÇÃO DE ENSINO & BIBLIOGRAFIA BÁSICA \\
\hline $\begin{array}{l}\text { UFU } \\
\text { Universidade } \\
\text { Federal } \\
\text { de Uberlândia }\end{array}$ & $\begin{array}{l}\text { GURGEL, Miriam. Projetando espaços: guia de arquitetura de interiores para áreas } \\
\text { comerciais. } 2^{2} \text { ed. Sảo Paulo: Senac São Paulo, } 2005.301 \text { p. } 1 \text { ex. } \\
\text { KARLEN, M. Planejamento de espaços internos. } 3^{2} \text { ed. Porto Alegre: Bookman, } 2010 \text {. } \\
240 \text { p. } \\
\text { MEEL, Juriaan van; MARTENS, Yuri; REE, Hermen Jan van. Como planejar os espaços } \\
\text { de escritórios: guia prático para gestores e designers. Barcelona: G. Gili, ano. } 144 \text { p. }\end{array}$ \\
\hline $\begin{array}{c}\text { IFAL } \\
\text { Instituto Federal } \\
\text { de Alagoas }\end{array}$ & 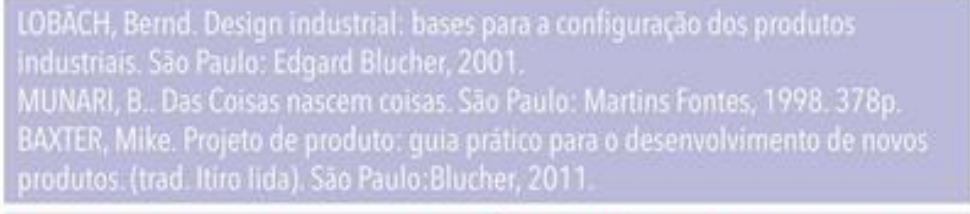 \\
\hline $\begin{array}{c}\text { IFPB } \\
\text { Instituto Federal } \\
\text { da Paraiba }\end{array}$ & $\begin{array}{l}\text { GIBBS, Jenny. Design de Interiores: Guia Útil para Estudantes e Profissionais. São } \\
\text { Paulo: G. Gilli, } 2005 \text {. } \\
\text { GURGEL, Miriam. Projetando espaços: guia de arquitetura de interiores para áreas } \\
\text { residenciais. São Paulo: Editora Senac. } 2003 \text {. } \\
\text { GURGEL, Miriam. Projetando espaços: guia de arquitetura de interiores para áreas } \\
\text { comerciais. São Paulo: Editora Senac.2005. }\end{array}$ \\
\hline $\begin{array}{c}\text { IFSP } \\
\text { Instituto Federal } \\
\text { de Săo Paulo }\end{array}$ & $\begin{array}{l}\text { CHING, F.D. Arquitetura de interiores ilustrada.3. ed. São Paulo: Bookman, } 2012 \\
\text { GURGEL, M. Projetando espaços: guia de arquitetura de interiores para áreas } \\
\text { residenciais. 5. ed. São Paulo: SENAC, } 2014 . \\
\text { KOWALTOWSKI, D.K. et ali. O Processo de Projeto em Arquitetura Da Teoria à } \\
\text { Tecnologia SaroPaulo: Oficina de Texto5, 2011. }\end{array}$ \\
\hline $\begin{array}{c}\text { IFMG } \\
\text { Instituto Federal } \\
\text { de Minas Gerais }\end{array}$ & $\begin{array}{l}\text { MACHADO, Maria Lúcia. Interiores no Brasil: a influência portuguesa no espaço } \\
\text { doméstico. São Paulo: Olhares, } 2011 . \\
\text { MORAES, Dijon. Limites do design. São Paulo: Studio Nobel. } 1997 \\
\text { ROAF, S.; FUENIES, M.; THOMAS.REES, S. Ecohouse: a casa ambientalmente } \\
\text { sustentável. 4" ed. Porto Alegre: Bookman, 2014.488p. }\end{array}$ \\
\hline
\end{tabular}

Figura 1 - IES Federais com CS em Design de Interiores e as Bibliografias para Metodologia de Projeto

Fonte: Autoras (2019)

\section{RESULTADOS E DISCUSSÃO}

A primeira metodologia a ser apresentada é a proposta por Jenny Gibbs (2010). Abaixo uma representação das etapas da metodologia proposta pela autora:

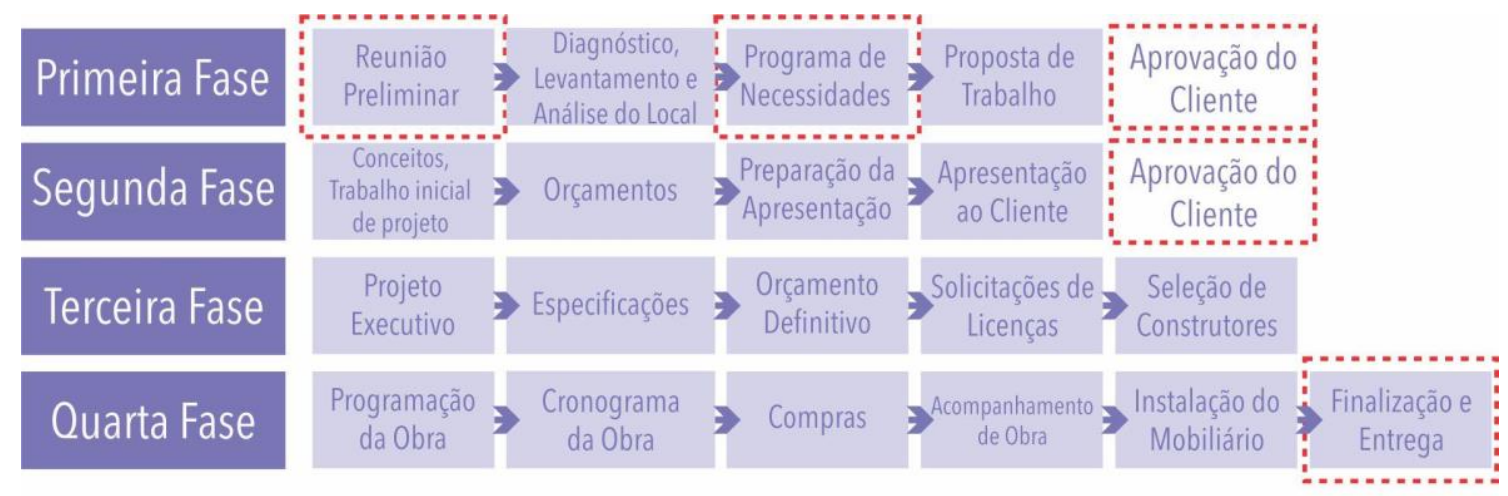

Etapas de

contato com 0

usuário

Figura 2 - Fases da Metodologia proposta por Gibbs (2010) e sinalização daquelas em que há relação com o usuário

Fonte: Autoras (2019) 
O método da autora possui uma estrutura linear, e os momentos do projeto que possuem consulta ao usuário e busca por suas preferências e necessidades são "Reunião preliminar" e "Programa de Necessidades". Moreira e Kowaltowski (2009) discutem a importância do programa de necessidades, para os autores

\begin{abstract}
seu objetivo é listar as condições do contexto onde um edifício irá operar em termos de requisitos funcionais. Trata-se da apresentação dos fatores de desempenho que se espera que a edificação cumpra e cujo objetivo principal é manter a integridade dos usuários e dos bens que abriga, ao corresponder aos seus anseios e expectativas de conforto e satisfação nesse mesmo espaço. O projeto de um edifício depende da correta observação desses requisitos, não só para cumprir metas, mas para estimular o seu uso nas mais variadas situações. (p.33)
\end{abstract}

No processo de projeto apresentado pela autora, percebe-se que não há uma "re-consulta" ao usuário em busca de feedbacks após o programa de necessidades. A autora sugere que sejam realizadas entrevistas junto ao cliente para o desenvolvimento do programa, mas não cita outras ferramentas que auxiliem o profissional na busca por informações mais subjetivas com relação ao usuário. Durante o processo, segundo Gibbs (2010), muitas vezes o designer opta por aplicar criações e estratégias de projeto já utilizadas anteriormente, ao invés de planejar algo novo e específico para o usuário em questão, tendo em vista por exemplo, os prazos a cumprir ou propostas que já deram certo anteriormente. Segundo Oliveira (2016) não há clareza de ferramentas específicas a serem utilizadas na abordagem junto ao usuário, sendo o requisito básico a habilidade e experiência do profissional. O autor comenta que, na "finalização e entrega", a etapa do método de Gibbs, não fica claro se há alguma verificação quanto à satisfação do cliente e/ou usuário .

Outro método apresentado abaixo é o de Gurgel (2007). Trata-se de uma abordagem mais simples, com menos etapas, e igualmente a descrição das atividades a serem realizadas é sucinta, por parte da autora.

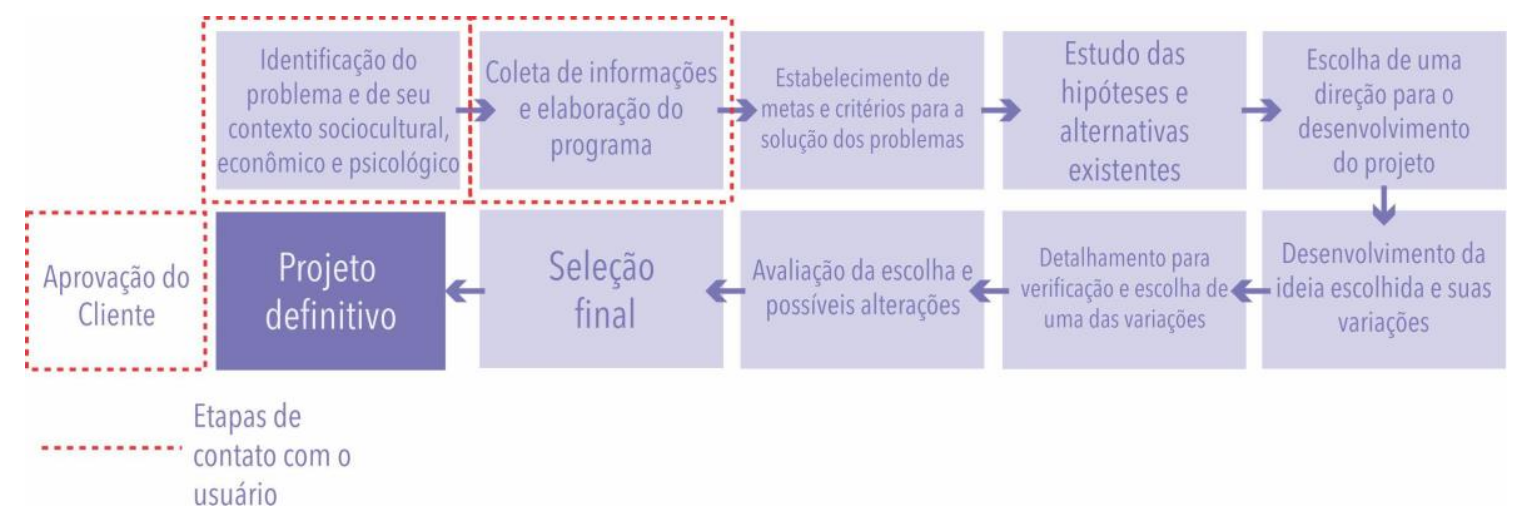

Figura 3 - Fases da Metodologia proposta por GURGEL (2007) e sinalização daquelas em que há relação com o usuário Fonte: Autoras (2019)

Neste método, também linear, o momento em que o usuário é considerado é na Primeira Ełapa, também denominada "Briefing" ou "Programa de Necessidades". Neste método, a necessidade de consulta ao usuário para possíveis ajustes no projeto não fica clara. 
Para Iwata, Rocha e Saleiro Filho (2003) a questão do método projetual no âmbito acadêmico tem por função principal a desmistificação do projeto, sua compreensão não apenas como uma ação criativa, artística, inspiracional, mas como um ato racional, que inclui métodos que podem e devem ser ensinados, reproduzidos. No entanto, para o autor, as questões de natureza psicológica que envolvem o processo de projeto não devem ser deixadas de lado, pois são habilidades a serem exercitadas pelo profissional em formação, bem como os referenciais teóricos e de projeto também devem embasar os processos intuitivos e criativos.

Para Ching e Binggeli (2013) o projeto de interiores diz respeito à intervenção no espaço interno à edificação, e contempla planejamento, layout e projeto. Para eles, esses ambientes são o palco da maior parte das nossas atividades e tem relação direta com nossas ações e aspirações influenciando nosso humor e nossa personalidade. Os autores afirmam que um projeto interior deve visar a melhoria da funcionalidade, da estética e das questões psicológicas desses espaços.

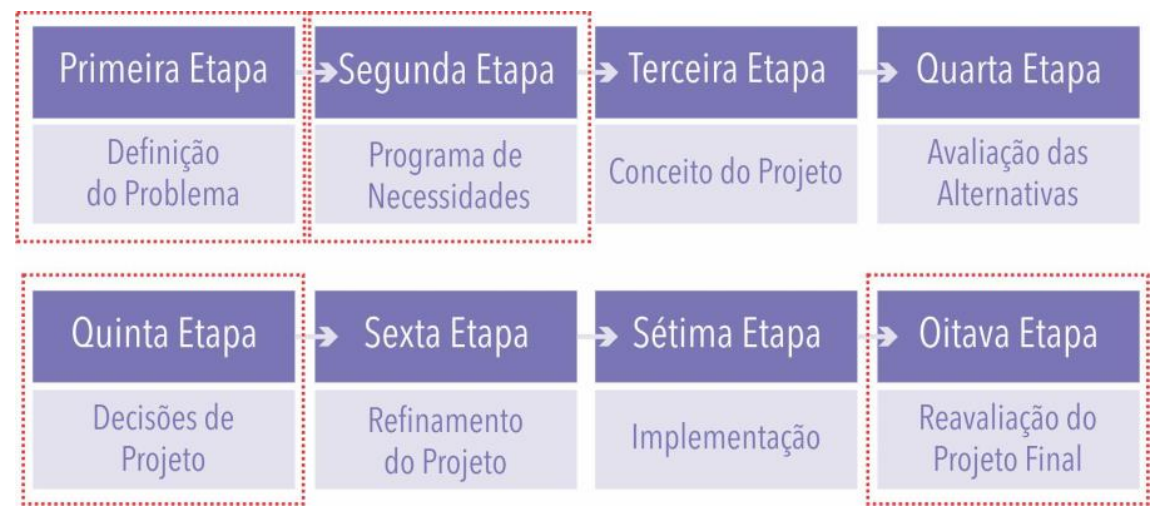

\section{Figura 4 - Fases da Metodologia proposta por CHING E BINGGELI (2013) e sinalização daquelas em que há relação com o usuário/ou cliente}

Fonte: Autoras (2019)

Dentro da etapa "Coleta de Informações" Ching e Binggeli (2013) sugere que se identifique as necessidades do "cliente", definindo-se "quem, o que, quando onde, como e porque", para então se estabelecer os objetivos preliminares. Sobre a etapa de "Elaboração do Programa de Necessidades", o autor sugere que se divida em três questões a serem respondidas: "O que existe", "O que se deseja" e "O que é Possível". Na primeira questão o "arquiteto de interiores" deverá coletar e analisa informações relevantes, documentando o contexto físico-cultural do usuário. Para responder ao segundo questionamento, deverá identificar as necessidades e preferências do usuário, e então desenvolver matrizes e diagramas para auxiliar nas definições espaciais. Esse autor, em especial, sugere que, se uma hipótese de problemática não for consistente, deverá ser reformulada. Neste caso há uma retroalimentação no sistema de projeto com base em uma possível não aprovação do cliente no meio do processo. Ao final da quinta etapa, denominada "Decisões de Projeto", o autor sugere que se monta uma apresentação ao cliente a fim de "obter um retorno e uma aprovação preliminar". Os autores sugerem tal apresentação ao cliente, não referindo-se a algum tipo de feedback por parte dos usuários. 
Na oitava etapa, denominada "Reavaliação do Projeto Final" o autor sugere que se busque um retorno do cliente e em seguida seja realizada uma APO.

A metodologia proposta por Mark Karlen (2009) possui um fluxo de etapas um pouco diferente. Em seu livro Planejamento de Espaços Internos, o autor não apresenta um diagrama com as etapas do seu processo de projeto, por isso apresenta-se abaixo uma ideia de como as etapas descritas pelo autor se desenvolvem, de acordo com sua descrição.

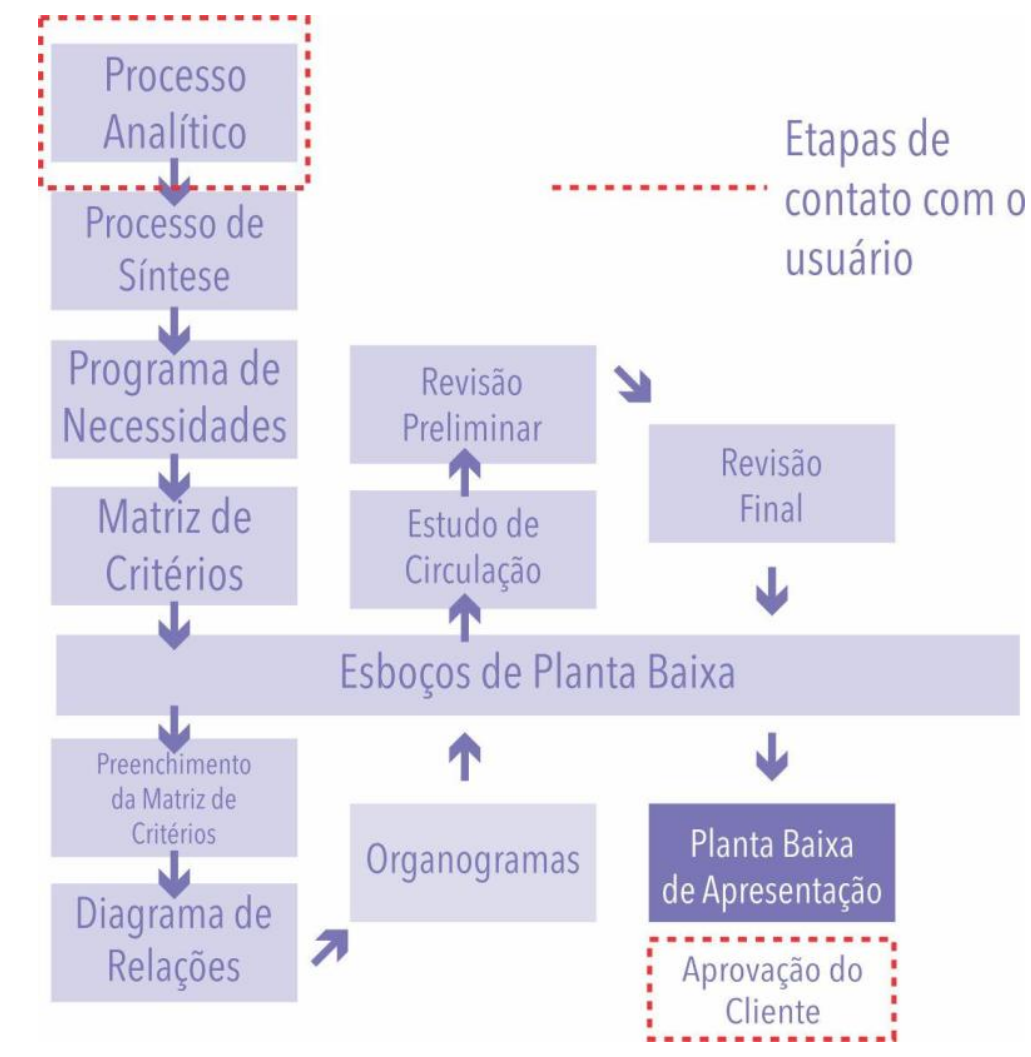

Figura 5 - Fases da Metodologia proposta por CHING E BINGGELI (2013) e sinalização daquelas em que há relação com o usuário/ou cliente

Fonte: Autoras (2019)

Com relação ao planejamento de espaços interiores e o usuário, o autor sugere que as informações costumam ser apresentadas ao projetista de maneira desordenada por "usuários sem experiência de projeto", e que aquele que contrata este tipo de serviço (cliente) costuma já ter refletido bastante sobre suas necessidades espaciais. O livro do autor dá ênfase ao projeto de interiores corporativos e institucionais, onde os usuários costumam ser os colaboradores das empresas. No diagrama acima sinaliza-se apenas dois momentos de contato com o cliente: um momento inicial, no qual definese o programa de necessidades do projeto - e nesse caso faz-se contato com o cliente e, em algumas situações, com algum usuário específico; e um momento final, de apresentação e aprovação do cliente. No entanto, o autor afirma que para se obter informações com relação aos usuários, fluxo de atividades e demais informações fundamentais, é possível falar com um gerente ou "funcionário chave" dentro da empresa. Ainda, segundo Karlen, caso um programa completo seja fornecido pelo contratante, o mesmo desenvolverá 0 projeto sem se responsabilizar pelo levantamento de informações. O autor não aponta ferramentas para abordagem dos usuários 
ou maneiras de se obter informações importantes como: atividades desenvolvidas, dificuldades enfrentadas, questões ergonômicas (física, cognitiva e organizacional), porém descreve de maneira detalhada ferramentas que auxiliam no processo de criação e diagrama de fluxos para definição do layout da empresa.

\section{CONSIDERAÇÕES FINAIS}

Este artigo apresentou, de maneira sintética, uma análise das metodologias de projeto propostas atualmente em instituições de ensino federais que oferecem formação para profissionais designers de interiores. Percebeu-se que a bibliografia sugerida é proveniente das áreas de design de produto, arquitetura e design de interiores. Dentre essas, as metodologias específicas para projetos de design de interiores possuem estrutura linear, etapas similares ao projeto arquitetônico, porém com adaptação básica, e o contato com o usuário costuma ocorrer nas etapas iniciais, não sendo comum verificar-se a sugestão da retomada desse contato, visando por exemplo, possíveis ajustes projetuais. Ferramentas que ofereçam subsídios para a busca de informações nos mais diferentes níveis - funcionais, psicológicos, cognitivos - também não são sugeridas. Percebe-se também que não há uma diferenciação clara sobre os termos "cliente" e "usuário", tendo em vista que nem sempre trata-se do mesmo indivíduo. Muitas vezes um cliente contrata o projeto (residencial, comercial, institucional, corporativo entre outros) no entanto haverá muitos usuários envolvidos no processo, e isso não costuma ser esclarecido ao longo das bibliografias.

A formação de profissionais com habilidades "polivalentes" e multidisciplinares é apontada por autores como o ideal para suprir as complexidades que o projeto de interiores demanda. O meio educacional conta, muitas vezes, com experiências de projetos reais, no entanto a literatura não é clara quanto aos procedimentos que o profissional em formação deverá aplicar para que as necessidades dos usuários sejam completamente atendidas.

Do ponto de vista do Design o usuário não deve ser apenas é um mero entrevistado, mas deve participar de todo o processo de desenvolvimento, sendo consultado constantemente em uma construção colaborativa. Percebe-se um grande desenvolvimento teórico acerca da importância da consideração do usuário e as relações estabelecidas com o ambiente, principalmente no contexto da psicologia ambiental, ergonomia e nos estudos de APO, no entanto pouco encontra-se sobre bases operacionais que orientem o profissional em formação sobre como estabelecer um processo empático com o usuário, seja por meio de observações ou outras ferramentas, que permitam o desenvolvimento de um projeto primando pela qualidade do projeto e pela satisfação do usuário. Percebe-se neste artigo uma lacuna importante para ser revista, visto que as áreas de design de produto e webdesign já vem desenvolvendo métodos projetuais centrados nos usuários e voltados à sua experiência. 


\section{REFERÊNCIAS}

CADASTRO NACIONAL DE CURSOS E INSTITUIÇÕES DE EDUCAÇÃO - CADASTRO E-MEC. Discponível em: <http://emec.mec.gov.br/>. Acesso em: 05/03/2019.

COSTA, Ana Paula Lima; VILLAROUCO, Vilma. METODOLOGIA DE CONFIGURAÇÃO DE AMBIENTE CONSTRUÍDO: UM CAMINHO PARA INTEGRAR A ERGONOMIA E A ARQUITETURA. Blucher Engineering Proceedings, v. 3, n. 3, p. 195-203, 2016.

CHING, Francis DK; BINGGELI, Corky. Arquitetura de interiores ilustrada. Bookman Editora, 2006.

ELALI, Gleice Azambuja. Psicologia e Arquitetura: em busca do locus interdisciplinar. Estudos de Psicologia (natal), [s.I.], v. 2, n. 2, p.349-362, dez. 1997.

GIBBS, Jenny. Design de interiores: guia útil para estudantes e profissionais. Ed. Gustavo Gili do Brasil, 2010.

GURGEL, Miriam. Projetando Espaços: Design de Interiores. São Paulo: Senac, 2007. 224 p.

IWATA, Nara; ROCHA, Ana Beatriz; SALEIRO FILHO, Mário. Interiores Exteriorizados/Exteriores Interiorizados:: $O$ ensino do projeto de arquitetura de interiores. In: I SEMINÁRIO NACIONAL SOBRE ENSINO E PESQUISA EM PROJETO DE ARQUITETURA - PROJETAR 2003 -, 1., 2003, Natal/rn. Anais... . Natal/rn: Ppgau/ufrn, 2003. p. 1 - 12.

KARLEN, Mark. Planejamento de espaços internos. Bookman Editora, 2009.

KOWALTOWSKI, Doris Catharine Cornelie Knatz et al. Reflexão sobre metodologias de projeto arquitetônico. Ambiente Construído, Porto Alegre, v. 6, n. 2, p.7-19, jun. 2006.

MERINO, Giselle Schmidt Alves Díaz. G ODP - Guia de Orientação para Desenvolvimento de Projetos: Uma metodologia de Design Centrado no Usuário. Florianópolis: Ngd/ Ufsc, 2016. Disponível em: (www.ngd.ufsc.brı. Acesso em: 01 abr 2018.

MOREIRA, Daniel de Carvalho; KOWALTOWSKI, Doris Catherine Cornelie Knatz. Discussão sobre a importância do programa de necessidades no processo de projeto em arquitetura. Ambiente Construído, v. 9, n. 2, p. 31-45, 2009.

MOSER, Gabriel. Psicologia Ambiental e estudos pessoas-ambiente: que tipo de colaboração multidisciplinar?. Psicologia Usp, [s.l.], v. 16, n. 1-2, p.131-140, 2005.

MUNARI, B. Das Coisas nascem coisas. São Paulo: Martins Fontes, 1998. 378p.

OLIVEIRA, Gilberto Rangel de. Método de Design de Interiores no Brasil: Uma contribuição dos princípios da Ergonomia do Ambiente Construído. 2016. 279 f. Tese (Doutorado) - Curso de Design, Departamento de Artes \& Design Puc-rio, Puc-rio, Rio de Janeiro, 2016. 